\title{
The Value of a Baseline Caries Risk Assessment Model in the Primary Dentition for the Prediction of Caries Incidence in the Permanent Dentition
}

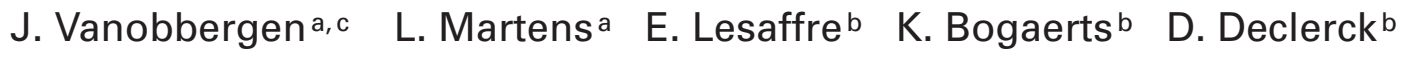 \\ aGhent University, Ghent, Belgium; bCatholic University of Leuven, Belgium; c Section Oral Health Promotion \\ and Prevention-Flemish Dental Association, Flanders, Belgium
}

\section{Key Words}

Caries prediction $\cdot$ Cohort study $\cdot$ Incidence .

Longitudinal $\cdot$ Schoolchildren

\begin{abstract}
To establish a reliable screening method for caries prediction and to identify predominant risk factors, this study tested whether a cross-sectional caries risk model assessed at age 7 could be used to predict future caries onset in the permanent first molars at age 10 in 3,303 children born in 1989. As prediction variables, assessing the believed risk, baseline data at age 7 on oral health status, oral hygiene level, oral health behaviour and sociodemographic factors were used. The real risk, based on data collected for the first permanent molars during the follow-up, was assessed by different approaches. Cumulative incidence during the 3-year observation period was $31.6 \%$, ranging from $22.4 \%$ in the believed lowrisk group to $43.2 \%$ in the believed high-risk group. A stepwise logistic regression analysis was performed with net caries increment as outcome measure, adjusted for the real time at risk, using eruption times. Baseline dmfs and occlusal and buccal plaque indices were highly significant for having a high caries increment in permanent first molars with respective odds ratios of 1.07, 1.43 and 1.35. Brushing less than once a day and the daily use of sugar-containing drinks between meals were confirmed as risk factors (OR 2.43 and 1.25 , re-
\end{abstract}

\section{KARGER}

Fax +4161306 1234

E-Mail karger@karger.ch

www.karger.com

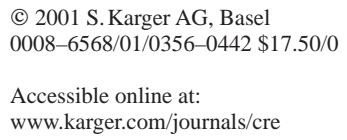

spectively). The logistic regression analysis provided a sensitivity of $59-66 \%$ and a specificity of $65.7-72.8 \%$, which indicates that the risk marker did not have an important predictive power. None of the socio-demographic and behavioural variables had enough predictive power at community level to be useful for identifying caries susceptible children. Even the power of dmfs at baseline must be considered modest.

Copyright $@ 2001$ S. Karger AG, Basel

The caries decline and the polarised distribution of caries experience drive us to develop a specific strategy to target preventive care or treatment to those individuals or groups identified as being at high risk for future caries development [Spencer, 1997]. The development of new and powerful diagnostic and biostatistical technologies would help us in this identification process. Together, the merging of these considerations forms the rationale for attempting to predict future caries increment by risk models based on longitudinal data [Stamm et al., 1991].

The most recent reviews and states of the art on caries prediction showed that:

(1) Due to the complex and multifactorial aetiology of the caries process, multiple risk models are needed to identify important risk factors and their interaction [Hausen, 1997; Beck, 1998].

(2) Probable and putative risk factors, detected in crosssectional studies, need to be confirmed by longitudinal stud-

Jackie Vanobbergen

Department Paediatric and Preventive Dentistry, Dental School, University Hospital

De Pintelaan 185

B-9000 Ghent Belgium

Tel. +329240 40 00, Fax +32924038 51, E-Mail jacques.vanobbergen@ @ug.ac.be 
ies (incidence rather than prevalence) [Powell, 1998; Beck, 1998].

(3) Clinical variables are stronger predictors than nonclinical variables and past caries experience is the most valuable [Disney et al., 1992; Hausen, 1997; Powell, 1998].

(4) Only a weak or no association could be demonstrated for socio-demographic variables [Disney et al., 1992], with the exception of prediction models for young children and elderly [Demers et al., 1990; Powell, 1998].

(5) When cariogenic bacterial levels are included they only moderately improve the fit of most prediction models [Disney et al., 1992; Hausen, 1997] .

(6) Logistic regression models using multiple factors and longitudinal data are the preferred analysis [Stamm et al., 1991; Beck, 1998; Powell, 1998].

Caries increment is the primary outcome measure in most longitudinal studies [Slade and Caplan, 2000]. There is no general agreement on which factors are most useful in identifying subjects with a high caries risk [FDI, 1988; Holbrook et al., 1993], or which is the best age group to screen at baseline [Demers et al., 1990, 1992; Powell, 1998]. Criteria are often determined by practical and theoretical considerations. It is reasonable to predict future caries and caries risk before the onset of any primary caries lesion [Hausen, 1997]. On the other hand, from a practical point of view it is more convenient to screen children when they start primary school. A caries screening programme for young children at the age of 6 was proposed to be the most economically feasible [Demers et al., 1992]. Because of compulsory school attendance, children attend mostly the same school for several years between 6 and 12 years of age.

Some limitations in the prediction literature have been observed. Caries incidence is mostly assessed using the caries increment among children attending both the baseline and the final examination, without taking into account the real time at risk. Some authors proposed incidence measures, such as cumulative incidence or incidence density, providing a more sensitive means of detecting high caries activity or risk [Slade and Caplan, 1999, 2000]. Furthermore, with the exception of the North Carolina study [Disney et al., 1992] and the Zürich study [Steiner et al., 1992], small sample size groups were used to identify high risk groups.

In Flanders (Northern Federal State of Belgium) the Signal-Tandmobiel ${ }^{\circledR}$ project was started in 1996 [Vanobbergen et al., 2000]. One of the objectives of this 6-year longitudinal project was to determine the oral health condition of primary schoolchildren between the ages of 7 and 12 years, both cross-sectionally and longitudinally. In an earlier cross-sectional study the impact of a set of risk indicators on caries prevalence in the primary dentition of 7-year-old Flemish children was defined. Gender, oral hygiene habits, use of fluorides, dietary habits, geographic factors and parental modelling were evaluated in a multiple model [Vanobbergen et al., 2001a, b].

In order to establish a reliable screening method for the prediction of caries and in order to test the validity of risk indicators, identified in cross-sectional studies, the aim of the present study was to evaluate, in a large sample, the caries-predictive ability of this baseline risk assessment model with respect to caries development in first permanent molars between the ages of 7 and 10 years.

\section{Material and Methods}

The present report is a 3-year longitudinal analysis of SignalTandmobiel data. The general set-up, along with a detailed description of the study sample and research methods used, was presented elsewhere [Vanobbergen et al., 2000]. Briefly, data were obtained from Flanders $(5,900,000$ inhabitants), where a cohort of schoolchildren representative of Flemish 7-year-olds (born in 1989) was selected from school data. Over 6,000 children (including longitudinal and cross-sectional control groups) were selected using cluster (school) sampling without replacement, stratified by province and educational system. Schools were selected with a probability proportional to their size, i.e. the number of children in the first year. They represented approximately $7 \%$ of the total target population. The experimental cohort was followed for 6 years in a prospective investigation (19962001). The selection criteria for the children to be included in the present study were: being born in 1989, belonging to the study group and having no missing covariates for the predictive model. They needed to have been examined at baseline and then at least once more during the following years (second, third or fourth examination). The baseline material consisted of 3,303 children, of whom 2,691 (81\%) remained at the final (fourth) examination. The effective sample size for the present analyses, being the number of children present for at least two examinations, including the first examination, was 3,002. The mean ages at baseline and at the fourth examination were 7.07 (SD 0.41) and 9.80 (SD 0.39) years, respectively.

Annually each child participated in oral health examinations on school premises in a mobile dental clinic. The dental examinations were conducted following standardised and widely accepted criteria, as recommended by the WHO [1987] report on oral health surveys. The diagnostic criteria for caries prevalence were these of the British Association for the Study of Community Dentistry [Pitts et al., 1997]. No radiographs were taken and decay was recorded at the level of cavitation, using a WHO/CPITN type E probe.

In order to register the level of oral hygiene, buccal surfaces of the Ramfjord teeth (primary alternatives) 16(55), 21(61), 24(64), 36(75), 44(84), 41(81) were scored according to the plaque index described by Silness and Löe [1964]. Plaque on occlusal surfaces of first permanent molars, where present, was assessed using a simplified version of the index of Carvalho et al. [1989].

For each year (= examination) and each permanent tooth, the eruption stage was recorded using the following coding: $0=$ non erupted or extracted; 1 = eruption stage 1 : occlusal surface only partially 
Table 1. Statistical values for significant variables in a cross-sectional multiple logistic regression analysis with dmfs (caries versus no caries) as dependent variable in 7-year-olds in Flanders $1996(n=3,303)$

\begin{tabular}{|c|c|c|c|c|c|}
\hline Variable & Estimate & SE & $\mathrm{p}$ value & OR & $95 \% \mathrm{CI}$ \\
\hline Intercept & -3.093 & 0.647 & $<0.001$ & 0.04 & $0.01-0.16$ \\
\hline \multicolumn{6}{|l|}{ Province } \\
\hline Antwerp & 1 & & & & \\
\hline Limburg (easternmost province) & +0.250 & 0.114 & 0.028 & 1.28 & $1.03-1.60$ \\
\hline West Flanders (westernmost province) & -0.332 & 0.109 & 0.002 & 0.72 & $0.58-0.89$ \\
\hline Age, years & +0.317 & 0.089 & $<0.001$ & 1.37 & $1.15-1.63$ \\
\hline \multicolumn{6}{|l|}{ Frequency of brushing } \\
\hline$\geq$ once a day & 1 & & & & \\
\hline$<$ once a day & +0.229 & 0.107 & $<0.03$ & 1.26 & $1.01-1.55$ \\
\hline Age at start of brushing, years & +0.199 & 0.035 & $<0.001$ & 1.22 & $1.14-1.30$ \\
\hline \multicolumn{6}{|l|}{ Regular use of systemic fluoride supplements } \\
\hline Yes & 1 & & & & \\
\hline No & +0.437 & 0.073 & $<0.001$ & 1.54 & $1.34-1.78$ \\
\hline \multicolumn{6}{|l|}{ Daily use of sugar-containing drinks } \\
\hline No & 1 & & & & \\
\hline Yes & +0.315 & 0.074 & $<0.001$ & 1.37 & $1.18-1.59$ \\
\hline \multicolumn{6}{|l|}{ In-between meal snacks } \\
\hline$\leq 2$ a day & 1 & & & & \\
\hline$>2$ a day & +0.214 & 0.078 & 0.006 & 1.24 & $1.06-1.44$ \\
\hline
\end{tabular}

This model included gender, educational system and province (stratification variables).

erupted (one cusp); 2 = eruption stage 2 : occlusal surface fully erupted, but less than half of the buccal surface erupted; $3=$ eruption stage 3: more than half of the buccal surface erupted, no antagonistic contact, and 4 = eruption stage 4 : fully erupted and full occlusal contact.

To ensure reliability, attention was paid to intensive training of the examiners and to continuing reinforcement of the diagnostic criteria during annual calibration exercises. For all 16 dentist examiners the level of intra- and inter-examiner agreement (kappa >0.6) obtained was acceptable [Landis and Koch 1977].

Additional to the clinical examination, data were collected on reported oral hygiene and dietary habits, use of fluorides, dental attendance, medical history and socioeconomic background of the children using questionnaires completed annually by parents and school health care centres.

\section{Variables}

The real risk was assessed using different approaches. Using data collected for the four first permanent molars at each examination (DMFS 6 scores), different outcome measures were calculated and compared: net caries increment, cumulative caries incidence and caries incidence density. Net caries increment was determined for each child by subtracting the baseline $\mathrm{DMFS}_{6}$ score from the last available $\mathrm{DMFS}_{6}$ score. Cumulative incidence represented the proportion of children who developed new caries within the total observation period. This proportion was calculated by counting the number of children whose caries increment exceeded zero during the observation period and then dividing by the total number of children. Caries incidence density represented the average change in caries status per unit time relative to the number of surfaces at risk, in this study based on the eruption stages of the teeth. Incidence density was expressed in newly affected surfaces (increment) per 100 surface years [Slade and Caplan, 2000].

For each child the 'real exposure time' or time at risk for the first permanent molars was approximated by an index based on the eruption stage of the teeth and the period under investigation. The index was calculated as the sum of the eruption stages over the four first permanent molars and over the available observation period.

As prediction variables assessing the believed risk, baseline data on oral health status, oral hygiene level, reported oral health behaviour and socio-demographic factors were used. Baseline oral health status was expressed using the baseline dmfs and baseline oral hygiene level using the plaque index on the occlusal (PII_O) and buccal (PII_B) surfaces. Baseline oral health behaviour and socio-demographic factors were investigated in an earlier cross-sectional multiple regression study [Vanobbergen et al., 2001a, b] and are presented in table 1 . Based on this model the probability of being affected by caries at the age of 7 ('score 7') was determined for each child and used as an indicator for future caries onset. The values of 'score 7' were normally distributed.

\section{Statistical Analysis}

In order to quantify the real risk for caries development in first permanent molars in Flemish primary schoolchildren between the ages of 7 and 10, the cumulative incidence was calculated for the whole study group and for three classes of children based upon the quartiles of 'score 7'. The three classes (<Q1; Q1-Q3; $>$ Q3), represented low, moderate and high believed risk groups. The statistical significance for the difference in cumulative incidence was assessed by $\chi^{2}$ test. 


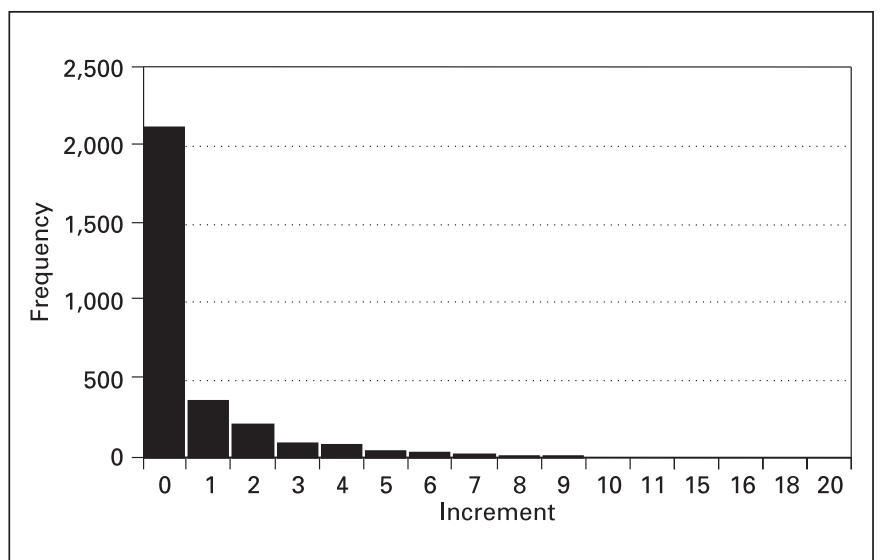

Fig. 1. Distribution of the net caries increment (DMFS) in first permanent molars in Flemish primary schoolchildren over a 3-year observation period.

To evaluate the predictive value of the independent variables, a multiple logistic regression analysis was performed with different outcome measures, both in an ordinal way and dichotomised with different cut-points. The best-fitting model was obtained using net caries increment as outcome measure including the 'real exposure time' as covariate. In agreement with the literature [Hausen, 1997] and considering the distribution, the net caries increment was dichotomised as 0 and 1 additional surface affected ( $83 \%$ of the subjects) versus 2 or more additional surfaces affected (17\%). Analyses with either the composite 'score 7' or with the separate variables were used. Odds ratios are reported together with their $95 \%$ CI. The level of significance was set at $\mathrm{p}<0.05$.

To get an idea of the predictive power different dichotomies were formed so that the selected threshold levels were distributed throughout the range of the independent variables. Such artificial dichotomising of both predictors and outcome allowed calculations for each level of 'believed high' versus 'believed low risk', of the sensitivity, specificity, true positives, true negatives, false positives, false negatives, positive predictive value and negative predictive value.

The information in the prediction models was summarised as ROC (receiver operating characteristic) curves and an index called: 'the area under the curve' $\left(\mathrm{A}_{\mathrm{z}}\right)$. The diagonal corresponds to a pure chance prediction $\left(A_{z}=0.50\right)$, while a perfect prediction is obtained at $\mathrm{A}_{\mathrm{z}}=1$. Statistical analyses were conducted using SAS, version 8 [SAS, 2000].

\section{Results}

The loss of children was $9 \%$. To check the influence of this drop-out, the distribution of the children with and without a follow-up was compared with regard to the variables age, province, educational system, gender, baseline dmfs and 'score 7'. In most of these variables no significant difference was observed (5\% level). Only in the stratification variables 'educational system' and 'province' a significant different was found $(\mathrm{p}=0.001)$. More children in the study group belonged to the 'free' educational system.

At baseline, $7.8 \%$ of the children had not a single erupted first permanent molar and $36 \%$ had four fully erupted permanent first molars. Of the 2,691 children examined at the final examination, $97.5 \%$ had four fully erupted first permanent molars. The net caries increment ranged from 0 ( $68.4 \%$ of the children) to 20 surfaces ( $0.1 \%$ of the children) over the study period (fig.1).

The cumulative incidence was rather high $(31.6 \%)$. The distribution according to the believed risk groups, based upon the quartiles of 'score 7', ranged from $22.4 \%$ in the 'believed low risk' group to $43.2 \%$ in the 'believed high risk'group. These differences were statistically significant $(\mathrm{p}<0.001)$.

The results of the stepwise multiple logistic regression analysis were based on the best fitting model, using net caries increment as outcome variable and the 'real exposure time' as covariate. Baseline dmfs, plaque indices and 'score 7' were used as predictors. The logistic model with the separate behavioural and socio-demographic factors was useful for evaluating each variable (table 2). The baseline dmfs and the plaque indices were highly significant for having a high caries increment. Behavioural and socio-demographic variables significant in the cross-sectional risk assessment model were checked one by one by stepwise inclusion. The stratification variables 'educational system' and 'province' were kept fixed in the model.

Brushing less than once a day and the daily use of sugarcontaining drinks between meals were confirmed as risk factors for developing a high caries increment in permanent first molars. The following variables, significant in the cross-sectional model, could not be confirmed in the longitudinal study: regular use of fluoride supplements; the consumption of more than two between-meal snacks per day and the child's age at start of brushing. The demographic factor 'province' remained an important risk predictor, with a lower risk when living in the western part of Flanders. The variable 'educational system' also came out significant, with an increased risk when attending municipal schools.

The assumption that the effect of a covariate on a logistic scale was equal for the transition from no caries to moderate caries increment (1 or more additional surfaces affected) and for the transition from moderate to high caries increment (2 or more additional surfaces affected) was verified in an ordinal logistic regression model for all variables and was not rejected at the 5\% level. 
Table 2. Odds ratio estimates and $95 \%$ confidence intervals after stepwise multiple logistic regression with net caries increment on first permanent molars as dependent variable (no or 1 additional surface affected versus 2 or more additional surfaces affected) and real exposure time as covariate in at baseline 7-year-old primary schoolchildren ( 3 years follow up; $\mathrm{n}=3,002$ )

\begin{tabular}{|c|c|c|c|c|c|}
\hline Variable & Estimate & SE & $\mathrm{p}$ value & Odds ratio & $95 \% \mathrm{CI}$ \\
\hline Intercept & -5.221 & 1.082 & $<0.001$ & & \\
\hline dmfs at 7 & +0.065 & 0.006 & $<0.001$ & 1.07 & $1.05-1.08$ \\
\hline PII_O & +0.355 & 0.120 & 0.003 & 1.43 & $1.28-1.80$ \\
\hline PII_B & +0.301 & 0.113 & 0.007 & 1.35 & $1.08-1.68$ \\
\hline Risk score at 7 & +0.558 & 0.117 & $<0.001$ & 1.75 & $1.39-2.20$ \\
\hline \multicolumn{6}{|l|}{ Educational system } \\
\hline Free (ref.) & 1 & & & & \\
\hline Community & +0.013 & 0.181 & 0.943 & 1.01 & $0.71-1.44$ \\
\hline Municipal & +0.348 & 0.134 & 0.009 & 1.42 & $1.09-1.84$ \\
\hline \multicolumn{6}{|l|}{ Province } \\
\hline Antwerp (ref.) & 1 & 1 & & & \\
\hline Limburg (easternmost province) & +0.264 & 0.159 & 0.098 & 1.30 & $0.95-1.78$ \\
\hline West Flanders (westernmost province) & -0.478 & 0.177 & 0.007 & 0.62 & $0.44-0.88$ \\
\hline Gender & +0.107 & 0.108 & 0.320 & 1.11 & $0.90-1.38$ \\
\hline \multicolumn{6}{|l|}{ Frequency of brushing } \\
\hline$\geq$ once a day (ref.) & 1 & & & & \\
\hline$<$ once a day & +0.808 & 0.141 & $<0.0001$ & 2.24 & $1.70-2.96$ \\
\hline Age at start of brushing, years & +0.070 & 0.050 & 0.156 & 1.07 & $0.97-1.18$ \\
\hline \multicolumn{6}{|l|}{ Regular use of systemic fluoride supplements } \\
\hline Yes (ref.) & 1 & & & & \\
\hline No & +0.005 & 0.110 & 0.963 & 1.01 & $0.81-1.25$ \\
\hline \multicolumn{6}{|l|}{ Daily use of sugar-containing drinks } \\
\hline No (ref.) & 1 & & & & \\
\hline Yes & +0.223 & 0.114 & 0.049 & 1.25 & $1.00-1.56$ \\
\hline \multicolumn{6}{|l|}{ In-between meal snacks } \\
\hline$\leq 2$ a day (ref.) & 1 & & & & \\
\hline$>2$ a day & -0.189 & 0.118 & 0.106 & 0.83 & $0.66-1.04$ \\
\hline
\end{tabular}

This model included gender, educational system and province (stratification variables).

Table 3 provides the information to answer the question how accurately future high caries increment can be predicted by using the studied explanatory variables. Each row corresponds to a $2 \times 2$ table. For the first row, the believed risk of new caries was considered high if the threshold of the predictor estimate selected $10 \%$ of the study cohort as highly caries-susceptible subjects. Correspondingly, the last row represents a prediction where risk was believed high for $50 \%$ of the children. The distribution of the subjects among the true positives, false positives, false negatives and true negatives varies strongly. Taking into account that the sensitivity cannot be useful if this value falls below $50 \%$ and that a balance with the specificity is desired, only two rows remain available to identify a manageable percentage of high-risk susceptible subjects, applying the cross-sectional baseline estimates as predictor. These rows provided a sensitivity ranging from 59 to $66 \%$ and a specificity between 65.7 and $72.8 \%$ and selected $30-40 \%$ of the children as being of believed high risk. The positive predictive value and negative predictive values were $29-31.5 \%$ and $89.3-90 \%$, respectively.

The ROC curve (fig. 2) summarises the predictive power of our risk marker. The curve lay above the diagonal and resulted in an $A_{z}$ of 0.72 , indicating rather low predictive power.

The information provided by baseline dmfs, separately or in combination with plaque indices on buccal and occlusal surfaces, and with 'score 7' is summarised in table 4 and visualised in figure 2 . The power of the risk function including all predictors was very similar to that of baseline 
Table 3. Prediction of high caries increment ( $>2$ newly affected surfaces) adjusted for real time at risk by baseline risk indicators and predictors a in a cohort of 3,002 initially 7-year-old children in Flanders (approximately 17\% of the children belonging to the true high-risk group)

\begin{tabular}{lllllllll}
\hline $\begin{array}{l}\text { Threshold } \\
\text { probability level } \\
\text { of believed } \\
\text { high risk }^{\mathrm{b}}\end{array}$ & $\begin{array}{l}\text { True } \\
\text { positives }\end{array}$ & $\begin{array}{l}\text { False } \\
\text { positives }\end{array}$ & $\begin{array}{l}\text { False } \\
\text { negatives }\end{array}$ & $\begin{array}{l}\text { True } \\
\text { negatives }\end{array}$ & Sensitivity & Specificity & $\begin{array}{l}\text { Positive } \\
\text { predictive } \\
\text { value }\end{array}$ & $\begin{array}{l}\text { Negative } \\
\text { predictive } \\
\text { value }\end{array}$ \\
\hline $10 \%$ & 125 & 164 & 351 & 2,079 & 26.3 & 92.7 & 43.2 & 85.5 \\
$15 \%$ & 159 & 223 & 317 & 2,020 & 33.4 & 90.1 & 41.6 & 86.4 \\
$20 \%$ & 200 & 332 & 276 & 1,911 & 42.0 & 85.2 & 37.6 & 87.4 \\
$25 \%$ & 244 & 462 & 232 & 1,781 & 51.2 & 79.4 & 34.6 & 88.4 \\
$30 \%$ & 281 & 610 & 195 & 1,633 & 59.0 & 72.8 & 31.5 & 89.3 \\
$40 \%$ & 314 & 769 & 162 & 1,474 & 66.0 & 65.7 & 29.0 & 90.0 \\
$50 \%$ & 335 & 955 & 141 & 1,288 & 70.4 & 57.4 & 25.2 & 90.1 \\
\hline
\end{tabular}

Missing values: 283.

a Baseline risk indicators and predictors, assessing the believed risk, were based on baseline data on oral health status, oral cleanliness, reported oral health habits and socio-demographic factors.

b Proportion of children believed to have a high caries risk.

Table 4. Areas under the ROC curves constructed by a stepwise logistic regression model with all predictors and risk indicators included as independent variables for predicting a caries increment of $\geq 2$ newly affected surfaces and adjusted for the real time at risk (17\% of the children belonging to the high-risk group)

\begin{tabular}{lr}
\hline & $\begin{array}{l}\text { Stepwise multiple } \\
\text { logistic regression }\end{array}$ \\
\hline $\begin{array}{l}\text { Baseline dmfs only } \\
+ \text { Plaque index occlusal surfaces and plaque }\end{array}$ & $0.691(\mathrm{p}<0.001)$ \\
$\begin{array}{l}\text { index buccal surfaces } \\
+ \text { Score } 7 \text { a }\end{array}$ & $0.695(\mathrm{p}<0.001)$ \\
\hline a Prediction variable, assessing the believed risk at baseline, based \\
$\begin{array}{l}\text { on reported oral health habits and socio-demographic factors, investi- } \\
\text { gated in a cross-sectional multiple regression model. }\end{array}$
\end{tabular}

dmfs score alone. Almost all the predictive power of the logistic regression function came from the baseline $\mathrm{dmfs}$, but the additional impact of the remaining predictors or indicators was statistically significant $(\mathrm{p}<0.001)$.

\section{Discussion}

\section{Outcome Measure}

An important issue in the evaluation of caries risk assessment is the use of an accurate and appropriate outcome measure. Cumulative incidence, as a proportion of children who developed caries within the 3-year observation period,

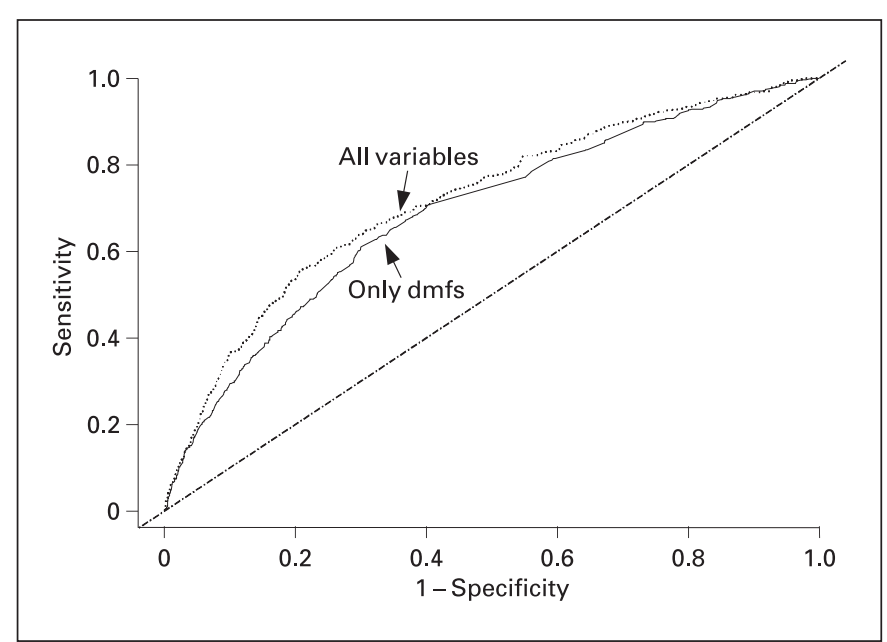

Fig. 2. ROC curves illustrating the relationship of sensitivities and specificities at different threshold levels (table 3) when baseline dmfs only or all baseline risk indicators and predictors were used as predictor for a caries increment of $\geq 2$ newly affected surfaces, adjusted for the real exposure time (area under the curve 0.69 and 0.72 , respectively).

forms a good notion of caries risk [Slade and Caplan, 2000]. In fact, in $32 \%$ of Flemish primary schoolchildren the first permanent molars tend to become carious during the first 1-3 years after eruption.

Cumulative incidence varied significantly throughout the range of 'believed risk' groups, from $22.4 \%$ in the 'believed low-risk' to $43.2 \%$ in the 'believed high-risk' group and could in this way give an indication of the predictive 
value of the studied prediction model, at least at community level. However, several factors, not included in the cumulative incidence measure, have to be taken into account: the loss of subjects, the substantial differences in real risk period, depending on different emergence timing and available observation time, and the large group of children with no caries increment $(68.4 \%)$. The loss of children (9\%) was minimised by the use of an appropriate outcome measure (net caries increment, adjusted for the real time at risk). From the initial selection (3,303 children), 3,002 were left for the logistic regression procedure. This was mainly due to refusals, moving or children who had to stay down in a class for an extra year. The influence of this loss of children on the results of the analyses was checked (see above).

Caries incidence density includes the real exposure time and minimises the loss of children, but cannot point out the differences in risk within the large group of children with no caries increment during the investigation period but having different exposure times for the different involved teeth. For that reason the final choice for the present analyses was the logistic procedure with net caries increment, adjusted for the real exposure time, as outcome measure. This procedure gave us the best fitting models and the most useful results.

\section{Validation of Risk Indicators}

Within the objectives of this study a variety of identified risk indicators, assessed in a previous cross-sectional study, were investigated. Potentially positive risk factors and potential protective factors were combined as proposed in the scientific literature [Leverett et al., 1993]. 'Daily use of sugar containing drinks' was confirmed to be a behavioural risk factor. 'Frequency of brushing' was the most important protective factor. The fact that the majority of the children (99\%) used a fluoridated toothpaste could indicate the major importance of the topical effect of fluorides in the prevention of dental decay in the permanent dentition. 'Age at start of brushing' and 'regular use of systemic fluoride supplements', found to be highly significant for explaining presence of caries in the primary dentition at age 7 , were no longer significant risk factors in the permanent dentition. In the 80s in several studies the absence of a relationship between dietary habits and caries increment was observed [Lachapelle et al., 1990]. In more recent studies [Holbrook et al., 1993; Grindefjord et al., 1995] misuse of sugar was found to be an important risk factor for caries increment in pre-school children. The compensatory mechanism of regular use of fluorides for the misuse of sugar has been demonstrated in earlier studies in pre-school children [Holbrook et al., 1993].
Gender-related differences have been demonstrated in small sample studies [Raitio et al., 1996]. In the present study no association with gender has been observed, which conforms with the findings of large sample studies [Disney et al., 1992].

Socio-demographic factors, such as 'province' and 'educational system' were found to be important confounders in the caries risk assessment model. More in-depth investigations need to be done to find out the underlying reasons for this relationship. These variables may include confounding environmental factors, such as social and geographic influences. Results from initial cross-sectional analyses indicated the importance of deprivation levels and social inequalities [Vanobbergen et al., 2001b]. Previous risk assessment surveys found significant differences in caries increment in young children by social environmental factors such as parental education [Lachapelle et al., 1990; Demers et al., 1992; Grindefjord et al., 1995].

\section{Risk Predictors}

Both past caries experience and oral cleanliness were found to be very important risk predictors. This is in full agreement with previous findings [ter Pelkwijk et al., 1990; Helfenstein et al., 1991; Steiner et al., 1992; Disney et al., 1992; Mattiasson-Robertson and Twetman, 1993]

\section{Predictive Ability}

In order to evaluate how accurately children with high future caries increment can be identified by using the combined baseline risk indicator $(\mathrm{dmfs}$, plaque indices and 'score 7'), the information in table 3 needs to be analysed in more depth. The considerations mentioned in the 'Results' section leave only two rows that can be considered useful. This corresponds to a group of children, that has to be treated as high-risk susceptible, whose size equals 30 $40 \%$ of the target population. This is the utmost limit to justify the efforts and the expenses of a high-risk preventive strategy rather than a whole population strategy [Hausen, 1997]. Even more, for none of the cases did the predictive power reach the proposed combined sensitivity and specificity of $160 \%$, which has been suggested to be the minimum for a caries risk marker for targeting individualised prevention [Kingman, 1990]. The best combination ( $\mathrm{Se}=$ $59 ; \mathrm{Sp}=73$ ) equalled 132 . In previously published studies a number of workers have attempted to identify high-risk individuals and groups with varying degrees of success, depending on the age group, the baseline caries experience and the caries incidence rate of the study group. Several studies use a combination of tests for caries prediction, stressing past caries experience or salivary counts [ter Pelk- 
wijk et al., 1990; Helfenstein et al., 1991; Leverett et al., 1993]. Several other studies have examined the use of a wider range of factors in caries prediction, involving behavioural and socio-demographic factors. They were included in the prediction models [Demers et al., 1992; Disney et al., 1992; Holbrook et al., 1993] or used as confounders in mutans streptococci tests [Mattiasson-Robertson and Twetman, 1993; Petti and Hausen, 2000]. Their analyses predicted between 48.4 and $82.8 \%$ of high increment children (sensitivity) and between 70 and $93.7 \%$ of the low increment children (specificity). Comparable to the results presented in this paper with regard to age, sample size or incidence rate of the studied population are the prediction models of Disney et al. [1992] (wider range of factors, age and sample size) and Petti and Hausen [2000] (behavioural and demographic variables, age and incidence rate) with sensitivities of 59 and $48.4 \%$ and specificities of 83 and $76.3 \%$, respectively.

The positive predictive value was 29 or $31.5 \%$ depending on the threshold chosen, indicating that only approximately 1 out of 3 children, referred for possible extra preventive measures, would actually need them. In this particular case, in a population of children with a baseline caries prevalence of 56\%, this value is rather low. The negative predictive value shows that $90 \%$ of the children who tested negative in fact remained without caries increment, which is fairly good for a high-prevalence disease. These values are comparable with the large sample study values of the University of North Carolina with a positive predictive value of 0.49 and a negative predictive value of 0.88 [Disney et al., 1992].
From the proportional area of 0.72 under the ROC curve, the predictive power of the compound baseline indicator is far from being perfect.

Although the stepwise multiple logistic regression analysis indicated a statistically significant improvement for all predictors upon the baseline dmfs score, this improvement did not add usefully to the accuracy of the prediction model.

In conclusion, this longitudinal study confirmed several risk indicators assessed by a baseline cross-sectional survey. Brushing less than once a day and daily consumption of sugar-containing drinks were key behavioural risk factors for the development of high caries rates in Flemish primary schoolchildren. On the other hand the multifactorial aetiology of dental caries hampers the construction of models for identifying caries susceptible children in a more accurate way. Yet, none of the socio-demographic and behavioural variables had enough predictive power at community level to be useful as good caries predictors. Even the power of $\mathrm{dmfs}$ at baseline must be considered modest. Application of a prediction model as studied in this paper could be useful in a priori chosen groups with high levels of caries incidence or baseline caries experience, based on geographic and social parameters. Different outcome measures have been discussed within this paper with regards to their accuracy for application in a high-risk preventive strategy. Measures taking into account the real exposure time seem to be the most accurate.

\section{References}

Beck JD: Risk revisited. Community Dent Oral Epidemiol 1998;26:220-225.

Carvalho JC, Ekstrand KR and Thylstrup A: Dental plaque and caries on occlusal surfaces of first permanent molars in relation to stage of eruption. J Dent Res 1989;68:773-779.

Demers M, Brodeur JM, Mouton C, Simard PL, Trahan L, Veilleux G: A multivariate model to predict caries increment in Montreal children aged 5 years. Community Dent Health 1992;9: 273-281.

Demers M, Brodeur JM, Simard PL, Mouton C, Veilleux G, Frechette S: Caries predictors suitable for mass-screenings in children: A literature review. Community Dent Health 1990;7: $11-21$.
Disney JA, Graves RC, Stamm JW, Bohannan HM, Abernathy JR, Zack DD: The University of North Carolina Caries Risk Assessment study: Further developments in caries risk prediction. Community Dent Oral Epidemiol 1992;20:64-75.

FDI: Review of methods of identification of high caries risk groups and individuals. Techn Report No 31. Int Dent J 1988;38:177-189.

Grindefjord M, Dahllöf G, Nilsson B, Modéer T: Prediction of dental caries development in 1year-old children. Caries Res 1995;29:343348.

Hausen H: Caries prediction: State of art. Community Dent Oral Epidemiol 1997;25:87-96.

Helfenstein U, Steiner M, Marthaler TM: Caries prediction on the basis of past caries including precavity lesions. Caries Res 1991;25:372376.
Holbrook WP, de Soet JJ, de Graaff J: Prediction of dental caries in pre-school children. Caries Res 1993;27:424-430.

Kingman A: Statistical issues in risk models for caries; in Bader JD (ed): Risk Assessment in Dentistry. Chapel Hill, University of North Carolina Dental Ecology, 1990, pp 193-200.

Lachapelle D, Couture C, Brodeur JM, Sévigny J: The effects of nutritional quality and frequency of consumption of sugary foods on dental caries increment. Can J Public Health 1990;8: 370-375.

Landis JR, Koch GG: The measurements of observer agreement for categorical data. Biometrics 1977;33:159-174. 
Leverett DH, Proskin HM, Featherstone JDB Adair SM, Eisenberg AD, Mundorff-Shrestha SA, Shields CP, Shaffer CL, Billings RV: Caries risk assessment in a longitudinal discrimination study. J Dent Res 1993;72:538543.

Mattiasson-Robertson A, Twetman S: Prediction of caries incidence in schoolchildren living in a high and a low fluoride area. Community Dent Oral Epidemiol 1993;21:365-369.

ter Pelkwijk A, van Palenstein Helderman WH, van Dijk JWE: Caries experience in the deciduous dentition as predictor for caries in the permanent dentition. Caries Res 1990; 24: 65-71.

Petti S, Hausen HW: Caries prediction by multiple salivary mutans streptococcal counts in cariesfree children with different levels of fluoride exposure, oral hygiene and sucrose intake. Caries Res 2000;34:380-387.

Pitts NB, Evans DJ, Pine CM: British Association for the Study of Community Dentistry (BASCD): Diagnostic criteria for caries prevalence surveys 1996/97. Community Dent Health 1997;4:6-9.
Powell LV: Caries prediction: A review of the literature. Community Dent Oral Epidemiol 1998; 26:361-371.

Raitio M, Pienihäkkinen K, Scheinin A: Multifactorial modeling for prediction of caries increment in adolescents. Acta Odontol Scand 1996;54:118-121.

SAS version 6.12, copyright 1989-1996 SAS Institute Inc., Cary, NC, USA.

Silness J, Löe H: Periodontal disease in pregnancy. II. Correlation between oral hygie-ne and periodontal condition. Acta Odontol Scand 1964;22:121-135.

Slade GD, Caplan DJ: Methodological issues in longitudinal epidemiologic studies of dental caries. Community Dent Oral Epidemiol 1999;27:236-248.

Slade GD, Caplan DJ: Impact of analytic conventions on outcome measures in two longitudinal studies of dental caries. Community Dent Oral Epidemiol 2000;28:202-210.

Spencer AJ: Skewed distribution: New outcome measures. Community Dent Oral Epidemiol 1997;25:52-59.
Stamm JW, Stewart PW, Bohanan HM, Disney JA, Graves RC, Abernathy JR: Risk assessment for oral diseases. Adv Dent Res 1991;5:4-17.

Steiner M, Helfenstein U, Marthaler TM: Dental predictors of high caries increment in children. J Dent Res 1992;71:1926-1933.

Vanobbergen J, Martens L, Lesaffre E, Bogaerts K, Declerck D: Assessing risk indicators for dental caries in the primary dentition. Community Dent Oral Epidemiol 2001a;29:in press.

Vanobbergen J, Martens L, Lesaffre E, Declerck D: The Signal-Tandmobiel ${ }^{\circledR}$ project, a longitudinal intervention health promotion study in Flanders (Belgium): Baseline and first year results. Eur J Paediatr Dent 2000;2:87-96.

Vanobbergen J, Martens L, Lesaffre E, Decerlck D. Parental occupational status related to dental caries experience in 7-year-old children in Flanders (Belgium). Community Dent Health 2001b;18:in press.

WHO. Oral Health Surveys: Basic Methods, ed 3. Geneva, World Health Organisation, 1987. 